\title{
Delirium in the elderly admitted to an emergency hospital service
}

\author{
Delirium em idosos admitidos em um serviço hospitalar de emergência \\ Delirio en ancianos admitidos en un servicio hospitalario de urgencia
}

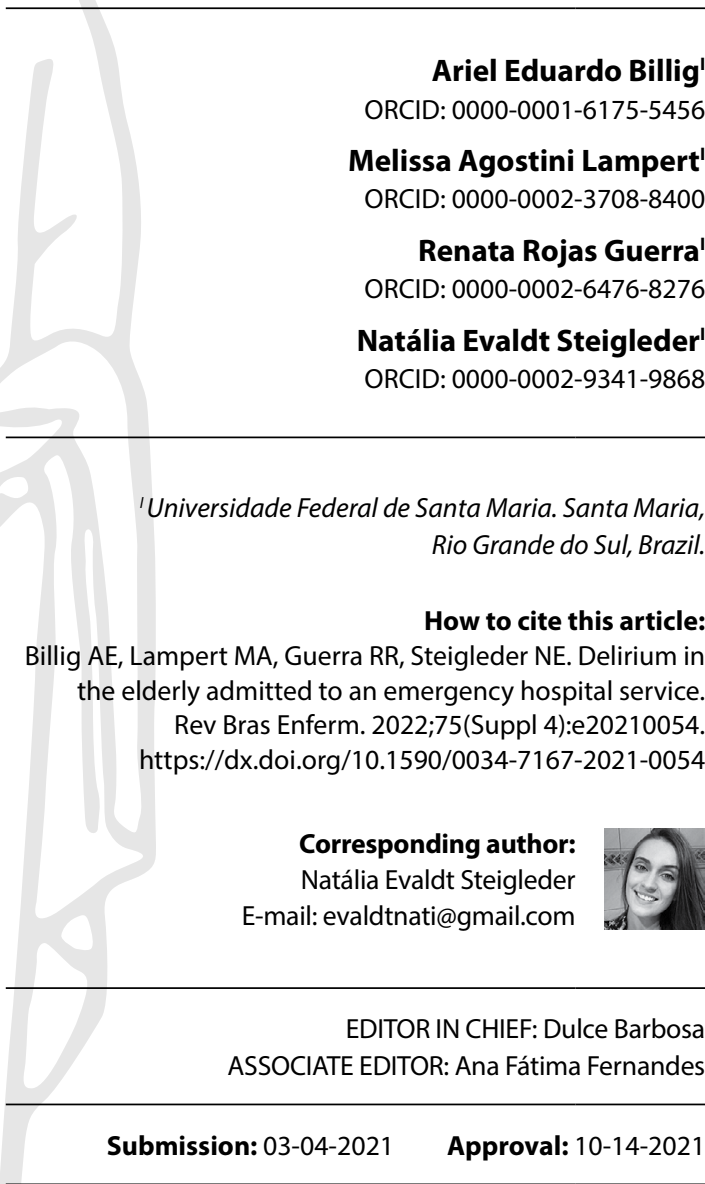

\begin{abstract}
Objective: To check for the presence of delirium in the elderly entering the emergency room (ER) of the University Hospital of Santa Maria (HUSM) and their relationship with sociodemographic variables, reason and time of hospitalization, comorbidities, and death. Methods: A quantitative, cross-sectional exploratory study, which analyzed data from the sociodemographic profile, Confusion Assessment Method, Charlson Comorbidities Index, and follow-up of the outcomes "in-hospital death" and"length of hospitalization."The period analyzed in the study was between July and December 2019. Results: Of the 732 participants, 394 (53.90\%) were men, with an average age of 72 years. The study identified Delirium in 99 (13.52\%) participants, and death, in $120(16.39 \%)$. There was an association of this disorder with age, comorbidities, length of hospitalization, death, and some reasons for hospitalization, such as diseases of the circulatory, respiratory and genitourinary systems. Conclusion: The results warn of the high incidence of delirium in emergency units and their relationship with a worse prognosis.

Descriptors: Delirium; Elderly; Emergency Service, Hospital; Death; Length of Hospitalization.
\end{abstract}

\section{RESUMO}

Objetivo: Verificar a presença de delirium em idosos que ingressam no pronto-socorro (PS) do Hospital Universitário de Santa Maria (HUSM) e sua relação com variáveis sociodemográficas, motivo e tempo de internação, comorbidades e óbito. Métodos: Estudo quantitativo, transversal exploratório, que analisou dados do perfil sociodemográfico, Confusion Assessment Method, Índice de Comorbidades de Charlson e seguimento dos desfechos "óbito intra-hospitalar"e "tempo de internação". O período analisado no estudo foi entre julho e dezembro de 2019. Resultados: Dos 732 participantes, 394 (53,90\%) eram homens, com idade média de 72 anos. Delirium foi identificado em 99 (13,52\%) participantes; e óbito, em 120 (16,39\%). Houve associação desse distúrbio com idade, comorbidades, tempo de internação, óbito e alguns motivos de internação, como doenças do aparelho circulatório, respiratório e geniturinário. Conclusões: Os resultados alertam para a alta incidência de delirium em unidades de emergência e sua relação com um pior prognóstico.

Descritores: Delirium; Idoso; Serviço Hospitalar de Emergência; Óbito; Tempo de Internação.

\section{RESUMEN}

Objetivo: Verificar presencia de delirium en ancianos que ingresan en hospital de urgencias del Hospital Universitario de Santa Maria (HUSM) y su relación con variables sociodemográficas, motivo y tiempo de internación, comorbilidades y óbito. Métodos: Estudio cuantitativo, transversal exploratorio, que analizó datos del perfil sociodemográfico, Confusion Assessment Method, Índice de Comorbilidades de Charlson y seguimiento de los desfechos "óbito hospitalaria" y "tiempo de internación". El período analizado en el estudio fue entre julio y diciembre de 2019. Resultados: Entre los 732 participantes, 394 (53,90\%) eran hombres, con edad mediana de 72 años. Delirio fue identificado en 99 (13,52\%) participantes; $y$ óbito, en 120 (16,39\%). Hubo relación de ese disturbio con edad, comorbilidades, tiempo de internación, óbito y algunos motivos de internación, como enfermedades del aparato circulatorio, respiratorio y genitourinario. Conclusiones: Los resultados alertan para la alta incidencia de delirium en unidades de urgencia y su relación con un peor pronóstico. Descriptores: Delirio; Anciano; Servicio de Urgencia en Hospital; Óbito; Tiempo de Internación. 


\section{INTRODUCTION}

Delirium can be considered an acute brain failure, the official definition of which is determined by the DSM-5 as a disorder in attention and consciousness that develops acutely, with varying severity throughout the day ${ }^{(1)}$. Its pathophysiological mechanisms are still unclear, but the main models indicate an imbalance of neurotransmitters and neuroinflammation ${ }^{(2)}$.

Despite being a syndrome common among hospitalized elderly, it continues to be poorly recognized and underdiagnosed, leading to worsening of the clinical picture and overload to the companion $^{(2)}$. Some time ago, specialists considered delirium a completely reversible event and the result of only one cause but today is known as the result of several factors and is linked to the possibility of developing severe sequelae ${ }^{(3)}$.

Its prevalence varies according to the adopted population, patient assessment period, and method used. Studies indicate that the incidence of delirium turns around $24 \%$ in patients after hip fracture. In the Intensive Care Unit (ICU), it can have a prevalence of $80 \%$; in an emergency sector, $37 \%$; and in long-stay institutions (ILPI), 40\%(4-6).

The result of periods of acute disturbance is worse in the long term since they directly increase the risk of falls, the length of hospitalization, hospital costs, the duration of mechanical ventilation, the degree of cognitive and functional impairment after hospitalization, as well as the chances of institutionalization and mortality ${ }^{(2-3,6)}$.

Prevention has proven to be the best way out, with the detection of the most fragile patient as the most important. Assessing the patient's clinical picture, his reserves, physical, cognitive, behavioral, and social disabilities is the first step towards building effective prevention strategies ${ }^{(7)}$.

The risks to delirium can be divided into predisposing and precipitating factors. Predisposing factors are alcoholism, chronic pain, history of lung, liver, kidney, heart, brain and/or terminal diseases, age over 65 years, male sex, dementia, depression, violence, falls, history of delirium, malnutrition, polypharmacy, pressure injuries, sensory insufficiency, decreased motor activity and social isolation. The main precipitating factors are dehydration, fracture, infection, ischemia, use of improper medications, disease in a high degree of severity, surgery, lack of pain control, urinary or stool retention, being in an ICU environment, sleep deprivation, and physical restraint. There are still some drugs that are inducers of delirium, with anticholinergics, benzodiazepines, dopamine agonists, and meperidine being the most at risk. The medications of moderate degree are antibiotics, anticonvulsants, antihypertensive, antiviral, tricyclic antidepressants, among others ${ }^{(2,8-9)}$.

It is already a consensus in the literature and clinical practice in emergency services that the instrument Confusion Assessment Method (CAM) is the most effective way to identify delirium, which can assist the team for the diagnosis at admission or during the period of hospitalization of the patient. It has high sensitivity (94.1\%) and specificity (96.4\%), demonstrating credibility for use in clinical practice ${ }^{(2,8-10)}$.

In Brazil and around the world, emergency services are marked by the continuous movement of people, sounds, and noises every minute, building a chaotic and stressful environment for patients. These conditions will eventually be characterized as triggering factors to the development of cognitive impairments such as delirium ${ }^{(11)}$.

Although scholars widely investigated it in International Literature, this disorder is still little studied in Brazilian samples of the elderly, especially when the place of study is the hospital emergency. Therefore, this situation characterizes the present research as pertinent to the scientific field.

\section{OBJECTIVE}

To check for the presence of delirium in the elderly entering the emergency room (ER) of the University Hospital of Santa Maria (HUSM) and their relationship with sociodemographic variables, reason and time of hospitalization, comorbidities, and death.

\section{METHODS}

\section{Ethical aspects}

The study observed the ethical aspects according to Resolution No. 466, of December 12, 2012, of the National Research Council, which defines the regulatory standards for research involving human beings.

The Ethics Committee of the Federal University of Santa Maria (UFSM) approved the project. The collected data will be analyzed and published anonymously. The researcher assumes confidentiality concerning the research data. The term of free and informed consent is not necessary because the application of the instrument occurs independently of the research, as it is part of the assistance provided routinely.

\section{Design, period and place of study}

This study is part of the project entitled "Predictive Validity of a Complex Patient Identification Instrument in Hospital Admission (CPI)," which takes place at HUSM, being a quantitative, cross-sectional exploratory study guided by the STROBE tool. The study analyzed data relating to delirium, describing the sample profile and follow-up of the outcomes "in-hospital death" and "length of hospitalization."The period analyzed in the study was between July and December 2019.

HUSM is academically affiliated to UFSM, it is characterized as a general, public, and teaching hospital of tertiary level with $100 \%$ service focused on the Public Health System (SUS). It is a reference in urgency and emergency within the State of Rio Grande do Sul, serving a population that exceeds 1.2 million people, coming from 45 municipalities.

According to statistics sector data, HUSM generates 15,209 hospitalizations per year; 7,053 surgeries in the operating room and 17,158 in short outpatient surgeries; 2,125 births; 180,439 outpatient appointments attended, and 210,365 outpatient appointments scheduled, thus demonstrating 15\% absenteeism on the part of patients. There were also 30,254 emergency room visits and 1,013,405 examinations. Regarding the hospitalization of the elderly, the quantitative is around 4,370 per year in the entire hospital, being more than 2 thousand only in the ER. 


\section{Population or sample; criteria of inclusion and exclusion}

All elderly patients admitted to HUSM between July and December 2019 were included as the target population. The inclusion criteria of the participants were: age equal to or greater than 60 years at the time of admission to the emergency service and their evaluation by the $\mathrm{CPI}$ instrument within 48 hours after hospital admission. The exclusion criteria were: age less than 60 years, no CPI instrument evaluation within the stipulated period due to clinical instability, examinations, or transfer to another hospital unit. Thus, of the 1,027 elderly patients admitted to the emergency room of the hospital of this study between July and December 2019, 732 (71.27\%) were classified as eligible and included in the analysis.

\section{Study protocol}

The CPI is an instrument implemented in the ER in July 2019, being part of the daily practice of professionals to evaluate patients at the entrance door of the service. It was developed to characterize the profile of hospitalizations in the ER, giving subsidies for the implementation of institutional policies of reception more consistent with their reality, evaluating functional capacity, the impact of comorbidities, delirium as indicators of complexity for care requirements. Nursing professionals apply the instrument upon the first contact with the patient as part of hospital admission and care planning. It is available on the HUSM intranet and completed by the professional within 48 hours of hospital admission to the ER for all adult patients of this sector. This time was stipulated seeking to minimize extraneous factors that would cause confusion bias for the criteria involved in the instrument.

The application generates an automatic message to the responsible person who fills it up and to the assistant team informing whether or not the patient is considered complex. Also, it automatically stores the data in a database developed by the HUSM computer service to carry out the analysis of indicators.

The CPI includes several instruments, but the present research will analyze the data from the CAM and the Charlson Comorbidities Index (CCI). The CCl identifies 17 comorbidities divided into 19 clinical situations; each, with different scores, between 1 and 3, whose sum signals the chance of survival in one year. It considers a risk signaling score of 6 points or more. The study chose this instrument to evaluate the prognosis when patients are affected by different comorbidities at different levels, indicating an overview of the patient's severity. The CAM identifies the presence of delirium, and it is composed of five attributes: acute onset, fluctuating course, inattention, disorganized thinking, and altered level of consciousness. Signals risk when there is the presence of the first three associated with the fourth or fifth attribute ${ }^{(10,12)}$.

\section{Analysis of results and statistics}

The variables analyzed in the study are age, sex, the reason for hospitalization, marital status, if the patient lives with someone, in addition to the presence of delirium (Positive CAM) and impact of comorbidities (indicated by CCl), obtained using CPI. As outcomes, researchers defined the occurrence of death during hospitalization and the length of stay indicated in days, provided by the statistics sector of the hospital itself.

Concerning the reason for admission, the pathologies, as indicated by the International Classification of Diseases (ICD), were grouped in the following categories: infectious and parasitic diseases (A00 - B99), neoplasms (C00 - D48), mental and behavioral disorders (F00 - F99) diseases of the circulatory system (100 - 199), diseases of the respiratory system (J00 - J99) diseases of the digestive system (K00 - K93) diseases of the genitourinary system (N00 - N99) pregnancy, childbirth and the puerperium (O00 - O99), fractures, and injuries ( $\mathrm{S} 00$ - T98), and other external causes (V01 - Y98), and other causes may be (other codes).

The data was organized in an Excel database automatically generated through the CPI application. Data relating to the observation of the outcomes were added to this database. The program $R$, version 3.6 .3 carried out the statistical analysis. The presentation of categorical variables was performed using absolute and relative frequencies; for continuous variables, mean, standard deviation, median, minimum and maximum.

The study used the chi-square test to verify the association between the variables Sex and Death with delirium. The $t$ test evaluated the ratio between age and length of hospital stay with delirium, according to the verification of variance through the $F$ test. For the analysis of the marital status, whether the patient lives with someone, the reason for hospitalization, and the results of $\mathrm{CCl}$ concerning delirium, it employed Fisher's exact test. As a level of significance, it adopted the value of $5 \%$.

Researchers used multiple logistic regression to identify the factors associated with this syndrome and their respective odds ratios. For the selection of the model, they used the technique stepwise. After the choice, they used the ROC curve (Receiver Operating Characteristic) for quality evaluation. For the model, they only selected the significant variables $(P \leq 5 \%)$.

\section{RESULTS}

The sample presented in Table 1 is composed essentially of male subjects ( $n=394 ; 53.90 \%)$, aged between 60 and 97 years, mean of 72 years and standard deviation (SD) of \pm 8.62 , married or in a stable union $(n=369 ; 50.41 \%)$ and who do not live alone $(\mathrm{n}=704 ; 96.17 \%)$.

The main reasons that led them to seek ER were diseases related to the circulatory system $(n=221 ; 30.19 \%)$; followed by fractures and injuries $(n=101 ; 13.80 \%)$. The maximum hospitalization time was 83 days, and the Mean Time was 10.08 days, with an SD of \pm 10.92 (Table 1).

Table 1 indicates the results of the CAM instrument and signals the presence of delirium in 99 patients (13.52\%). At a significance level of $5 \%$, the findings indicate no association between sex ( $p$ $=0.2938)$, living with someone $(p=0.5681)$, marital status $(p=$ $0.4583)$ and reason for hospitalization $(p=0.0863)$ with delirium. The statistical analysis indicates that there is a statistically significant association between death and the results of $\mathrm{CCl}$ with delirium $(p<0,0001)$. 
Table 1 - Descriptive statistics of categorical variables related to delirium, Santa Maria, Rio Grande do Sul, Brazil, 2019

\begin{tabular}{|c|c|c|c|c|c|}
\hline \multirow[b]{2}{*}{ Variables $(\mathrm{N}=732)$} & \multicolumn{2}{|c|}{ Delirium } & \multirow{2}{*}{$\begin{array}{l}\text { Total } \\
\text { n (\%) }\end{array}$} & \multirow[b]{2}{*}{ Test used } & \multirow{2}{*}{$\begin{array}{c}p \text { value } \\
(\alpha=0.05)\end{array}$} \\
\hline & $\begin{array}{c}\text { Positive CAM* } \\
\text { n (\%) }\end{array}$ & $\begin{array}{c}\text { Negative CAM* } \\
\text { n (\%) }\end{array}$ & & & \\
\hline Sex & & & & Qui-square & 0.2938 \\
\hline Male & $48(6.56)$ & $346(47.27)$ & $394(53.90)$ & & \\
\hline Female & $51(6.97)$ & $287(39.21)$ & $338(46.10)$ & & \\
\hline Marital Status & & & & Fisher's exact & 0.4583 \\
\hline Married & $41(5.60)$ & $328(44.81)$ & $369(50.41)$ & & \\
\hline Single & $15(2.05)$ & $93(12.70)$ & $108(14.75)$ & & \\
\hline Widow & $28(3.83)$ & $152(20.77)$ & $180(24.59)$ & & \\
\hline Divorced / Separated & $9(1.23)$ & $53(7.24)$ & $62(8.47)$ & & \\
\hline Others & $6(0.82)$ & $7(0.96)$ & $13(1.78)$ & & \\
\hline Live with someone & & & & Fisher's exact & 0.568 \\
\hline No & $3(0.41)$ & $25(3.42)$ & $28(3.83)$ & & \\
\hline Yes & $96(13.11)$ & $608(83.06)$ & $704(96.17)$ & & \\
\hline Reason for admission & & & & Fisher's exact & 0.0863 \\
\hline Diseases of the circulatory system & $33(4.51)$ & $188(25.68)$ & $221(30.19)$ & & \\
\hline Fractures and injuries & $13(1.78)$ & $88(12.02)$ & $101(13.80)$ & & \\
\hline Neoplasms & $8(1.09)$ & $69(9.43)$ & $77(10.52)$ & & \\
\hline Diseases of the digestive tract & $6(0.82)$ & $64(8.74)$ & $70(9.56)$ & & \\
\hline Diseases of the respiratory system & $15(2.05)$ & $47(6.42)$ & $62(8.47)$ & & \\
\hline Diseases of the genitourinary system & $8(1.09)$ & $23(3.14)$ & $31(4.23)$ & & \\
\hline Infectious and parasitic diseases & $2(0.27)$ & $23(3.14)$ & $25(3.42)$ & & \\
\hline Other external causes & $4(0.55)$ & $44(6.01)$ & $48(6.56)$ & & \\
\hline Other causes & $10(1.37)$ & $87(11.89)$ & $97(13.25)$ & & \\
\hline Death & & & & Qui-square & $<0.0001$ \\
\hline Yes & $36(4.92)$ & $84(11.48)$ & $119(16.27)$ & & \\
\hline No & $63(8.61)$ & $549(75)$ & $612(83.72)$ & & \\
\hline Charlson comorbidities index & & & & Fisher's exact & $<0.0001$ \\
\hline $98 \%$ chance of survival & $37(5.05)$ & $5(0.68)$ & $42(5.73)$ & & \\
\hline $89 \%$ chance of survival & $21(2.86)$ & $296(39.07)$ & $317(43.30)$ & & \\
\hline $79 \%$ chance of survival & $44(6.01)$ & $186(25.40)$ & $230(31.42)$ & & \\
\hline $64 \%$ chance of survival & $29(3.96)$ & $114(15.57)$ & $143(19.53)$ & & \\
\hline Total & 99 (13.52) & $633(86.48)$ & & & \\
\hline
\end{tabular}

${ }^{*} C A M=$ Confusion Assesment Method.

It is relevant to point out that, by setting the significance level at $10 \%$, the category reason for hospitalization would be associated with delirium. The study verified that this result occurs because not all reasons for hospitalization are related to this disorder. By reclassifying this variable to group the diseases of the circulatory, respiratory and genitourinary system and separating them from the other reasons for hospitalization in a binary variable, it shows that the reason for hospitalization has a significant association with the delirium at a significance level of $5 \%(p=0.0031)$.
The results related to age and length of hospitalization also indicated an association with delirium, with $p<0.0001$ e $p=$ 0.0003 , respectively. The analysis of the hospitalization time of patients who evolved to death demonstrated significance in the relationship with delirium (0.0156) (Table 2).

Table 3 presents the final model using the stepwise. The final evaluation of the model using the area under the ROC curve showed good discrimination of the results, with a value equal to 0.6924 in a $95 \%$ confidence interval (Cl: 0.6378-0.7469).

Table 2 - Descriptive statistics of continuous variables related to delirium, Santa Maria, Rio Grande do Sul, Brazil, 2019

\begin{tabular}{|c|c|c|c|c|}
\hline \multirow{2}{*}{ Variables } & \multicolumn{2}{|c|}{ Delirium } & \multirow{2}{*}{ Test used } & \multirow{2}{*}{$\begin{array}{c}p \text { value } \\
(\alpha=0.05)\end{array}$} \\
\hline & Positive CAM* & Negative Cam* & & \\
\hline Age (years) & & & Teste $t$ & $<0.0001$ \\
\hline Mean $( \pm S D * *)$ & $75.49(8.92)$ & $71.58(8.46)$ & & \\
\hline Median & 74 & 71 & & \\
\hline Minimum-maximum & $60-96$ & $60-97$ & & \\
\hline Length of hospitalization (days) & & & Teste $t$ & 0.0003 \\
\hline Mean $\left( \pm S D^{* *}\right)$ & $10.17(9.64)$ & $10.06(11.12)$ & & \\
\hline Median & 8 & 7 & & \\
\hline Minimum-maximum & $0-64$ & $0-83$ & & \\
\hline Hospitalization time for patients with death (days) & & & Teste $t$ & 0.0156 \\
\hline Mean $\left( \pm S D^{* *}\right)$ & $8.77(7.43)$ & $13.42(13.12)$ & & \\
\hline Median & 6.5 & 10 & & \\
\hline Minimum-maximum & $0-28$ & $0-63$ & & \\
\hline
\end{tabular}

${ }^{*} C A M=$ Confusion Assessment Method; **SD = standard deviation. 
Table 3 - Multiple logistic regression model of the factors associated with delirium, Santa Maria, Rio Grande do Sul, Brazil, 2019

\begin{tabular}{|c|c|c|c|c|c|}
\hline Variables & Estimate & Default error & $\begin{array}{l}\text { Final Model } \\
\text { z Value }\end{array}$ & $\mathrm{OR}^{*}(95 \% \mathrm{Cl})$ & $p$ value \\
\hline (Intercept) & -6.4065 & 1.0064 & -6.37 & - & 0.0000 \\
\hline Diseases of the circulatory system & 0.6082 & 0.2565 & 2.37 & $1.84(1.11-3.04)$ & 0.0177 \\
\hline Diseases of the genitourinary system & 1.3103 & 0.4549 & 2.88 & $3.71(1.52-9.04)$ & 0.0040 \\
\hline Diseases of the respiratory system & 0.9888 & 0.3463 & 2.85 & $2.69(1.36-5.30)$ & 0.0043 \\
\hline Charlson & 0.0703 & 0.0420 & 1.67 & $1.07(0.99-1.16)$ & 0.0944 \\
\hline Age & 0.0517 & 0.0134 & 3.86 & $1.05(1.03-1.08)$ & 0.0001 \\
\hline
\end{tabular}

OR $=$ Odds Ratio.

\section{DISCUSSION}

The results presented in this study demonstrate that the prevalence of delirium at ER is high ( $n=98,13.41 \%$ ), in line with that indicated in other Brazilian screening studies conducted in the same environment ${ }^{(13-14)}$. The results also match the findings of research carried out in the emergency services of other countries and a meta-analysis (7,15-16). $^{\text {. }}$

Age emerged as a variable strongly associated with delirium in this study $(p<0.0001)$. Several studies show that the disorder is age-dependent, that is, the older the age, the higher the chance of diagnosis, converging with the results presented here (OR: 1.05; $\mathrm{Cl}(95 \%): 1.02-1.08)^{(17-19)}$. The sample was characterized, in its majority, by male individuals ( $n=394,53.90 \%)$, something common in research in the hospital environment, given the culture that discourages men to care for their health ${ }^{(14,20)}$.

Data related to death indicate a strong association with delirium ( $p<0.0001)$, and among the patients who died, 35 (4.79\%) were positive for this syndrome. The literature describes delirium as an independent predictor of mortality, with studies indicating a death rate between $6 \%$ and $15 \%$ in the emergency sector. In the present study, there was an association between time to death and delirium ( $p=0.0156)$, showing that subjects with the syndrome end up dying earlier, according to the indication in the literature ${ }^{(16,21-23)}$.

A Brazilian study conducted in an intensive care unit (ICU) found that death, when related to delirium, reaches a rate of more than $28 \%$. Another Brazilian study with elderly patients victims of femur fracture, pointed out that patients with such a disorder had approximately six times more chance of progressing to death ${ }^{(23-24)}$.

The model found in this study indicates that patients diagnosed with diseases of the circulatory system [OR: $1.81 ; 95 \% \mathrm{Cl}: 1.10-$ 2.99], genitourinary [OR: 3.68; 95\% Cl: 1.51-8.96], and respiratory [or: $2.68 ; 95 \% \mathrm{Cl}: 1.36-5.28]$ have greater chances of presenting delirium during their hospitalization since it corroborates to what was found in other studies, evidencing that the results presented here are satisfactory. The literature specifies the strong influence of diabetes, renal failure, and pneumonia as the principal diagnoses related to delirium ${ }^{(19)}$.

The findings also demonstrate a strong association between ICC and delirium ( $p<0.0001$ ), stating that patients with more coexisting diseases are more at risk of developing this syndrome during hospitalization. Relevant literature points out that cases of delirium not detected by the assistant team generally present a greater burden of comorbidities, indicating that the recognition of this disorder may be affected by the number and/or complexity of previous diagnoses. Other studies evaluating survival and readmission show a strong association between delirium and higher results in $\mathrm{CCl}$, increasing the chances of returning to the hospital and death during hospitalization and after discharge ${ }^{(19,25-28)}$.

The length of hospitalization of patients with delirium was higher when compared with those not diagnosed with the syndrome ( $p$ $=0.0003)$, ratifying the literature. A multicenter study conducted in Canada indicated that an episode of delirium increases hospital stay time by four days, so it has important implications for patients and can contribute to overcrowding ${ }^{(18,26,29)}$.

Regarding the reason for hospitalization and its relation to delirium, the specificity in the sample studied of diseases of the circulatory system is clear. Hypertension and diabetes mellitus are among the principal diseases that affect the elderly population in Brazil, causing significant limitations in the quality of life and increased mortality, which contributes to the development of cognitive impairments such as delirium ${ }^{(14,20)}$.

The literature extensively relates the diseases of the genitourinary system to delirium. In addition to generally being silent infectious conditions with less apparent symptomatology, they tend to require quite invasive practices, such as the use of a bladder probe ${ }^{(13,25)}$.

Despite the findings described here, the relationship between pathologies of the respiratory system and delirium is most commonly described in the literature in ICU or post-surgical settings, given the use of mechanical ventilation and the high risk of pneumonia after performing specific procedures ${ }^{(3,19,23)}$.

It is essential to highlight the absence of patients diagnosed with dementia in the sample, considering that, to date, there are no screening instruments for delirium validated for this specific population, which can generate a confounding factor for the data presented, considering some similarities in its manifestation. If there were patients diagnosed with dementia, they could not be part of the sample, which would characterize an exclusion criterion $^{(30)}$.

The number of Brazilian surveys involving delirium has been growing recently, but when it comes to the emergency sector, this number decreases again. Conducting a study in an emergency environment is a challenge already pointed out by the literature because it is a space marked by overcrowding, where professionals are usually overloaded, in poor working conditions, in search of the balance between the care of the critically ill patient and those who are waiting for a bed for hospitalization ${ }^{(31-32)}$. Such a scenario requires a research framework capable of covering these limitations, with selection criteria and sample size that 
suit the environment, but without losing its scientific rigor and generalization capacity. Therefore, the cross-sectional design was adequate to the requirements of the study site ${ }^{(33)}$.

\section{Study limitations}

The study limitations are those intrinsic to cross-sectional studies conducted in a single location, given its limited ability to generalize the results and inability to make causal inferences. In addition, the use of pre-existing clinical data restricted the number of variables and the overall adequacy of the data according to the clinical picture studied.

\section{Contributions to the fields of Nursing, Health or Public Policy}

The results described here are valuable for future analyses related to the impact of aging on practical issues of Health Services, clinical pictures with higher prevalence among the elderly, and their respective results, contributing to a more precise analysis of the situation of this population in hospital emergency services.

\section{CONCLUSION}

This study aimed to verify the incidence of delirium in the emergency sector, presenting relevant results that require greater attention, such as high incidence of the syndrome among the elderly and a strong relationship with death. Because it is reversible and exhibits such adverse outcomes for patients, the scientific community must turn its attention to this clinical picture, especially when observing the rapid demographic transition that the country faces.

The shortage of studies related to delirium in the elderly in Brazil is undeniable. This lack can lead to health professionals having less knowledge about its significant impact on the clinical evolution of the patient, as demonstrated in this study.

Therefore, it is necessary to investigate issues related to hospitalized elderly, especially in the emergency sector. Not modifying the behaviors and not adapting the protocols of care is a way of denying the aging of the population and its high demand for health care, causing preventable deaths, development of unnecessary limitations, and overcrowding.

\section{REFERENCES}

1. American Psychiatry Association (APA). Diagnostic and Statistical Manual of Mental Disorders - DSM5. 5th.ed. Washington: American Psychiatric Association, 2013.596 p.

2. Inouye SK, Westendorp RG, Saczynski JS. Delirium in elderly people. Lancet. 2014;383(9920):911-22. https://doi.org/10.1016/ S0140-6736(13)60688-1

3. Marcantonio ER. Delirium in Hospitalized Older Adults. N Engl J Med. 2017;377(15):1456-66. https://doi.org/10.1056/NEJMcp1605501

4. Yang Y, Zhao X, Dong T, Yang Z, Zhang Q, Zhang Y. Risk factors for postoperative delirium following hip fracture repair in elderly patients: a systematic review and meta-analysis. Aging Clin Exp Res. 2017;29(2):115-26. https://doi.org/10.1007/s40520-016-0541-6

5. Kersten A; Reith S. Delirium and delirium management in critically ill patients. ProCare. 2016;21(5):16-22. https://doi.org/10.1007/s00735016-0644-5 German

6. Han JH, Suyama J. Delirium and Dementia. Clin Geriatr Med. 2018;34(3):327-54. https://doi.org/10.1016/j.cger.2018.05.001

7. Hshieh TT, Inouye SK, Oh ES. Delirium in the Elderly. Psychiatric Clinics of North America. 2018;41(1): 1-17. https://doi.org/10.1016/j. psc.2017.10.001

8. Torales J, Barrios I, Armoa L. [Delirium: an update for internists and psychiatrists]. Rev Virtual Soc Parag Med Int. 2017;4(2):54-64. https://doi. org/10.18004/rvspmi/2312-3893/2017.04(02)54-064 Spanish

9. National Institute for Health and Clinical Excellence - NICE. Delirium: diagnosis, prevention, and managemen [Internet]. 2010 [cited 2020 Jul 2]. Available from: http://www.nice.org.uk/cg103

10. Fabbri RMA, Moreira MA, Garrido R, Almeida OP. Validity and reliability of the Portuguese version of the Confusion Assessment Method (CAM) for the detection of delirium in the elderly. Arq Neuropsiquiatr [Internet]. 2001 [cited 2020 May 18];59(2A):175-9. Available from: http://www.scielo.br/pdf/anp/v59n2A/a04v592a.pdf

11. Hare $M$, Arendts $G$, Wynaden $D$, Leslie $G$. Nurse screening for delirium in older patients attending the emergency department. Psychosomatics. 2014;55(3):235-42. https://doi.org/10.1016/j.psym.2013.08.007

12. Charlson ME, Pompei P, Ales KL, MacKenzie CR. A new method of classifying prognostic comorbidity in longitudinal studies: development and validation. J Chronic Dis. 1987;40(5):373-83. https://doi.org/10.1016/0021-9681(87)90171-8

13. Rosso LH, Gomes GA, Maronezi LF, Lindemann IL, Riffel RT, Stobbe JC. Delirium in elderly inpatients in emergency units: a prospective study. J Bras Psiquiatr. 2020;69(1):38-43. https://doi.org/10.1590/0047-2085000000261

14. OhI ICB, Chavaglia SRR, OhI RIB, Lopes MCBT, Campanharo CRV, Okuno MFP, et al. Evaluation of delirium in aged patients assisted at emergency hospital service. Rev Bras Enferm. 2019;72(Suppl 2):153-60. https://doi.org/10.1590/0034-7167-2018-0386

15. Han JH, Wilson A, Schnelle JF, Dittus RS, Wesley EE. An evaluation of single question delirium screening tools in older emergency department patients. Am J Emerg Med. 2018; 36(7):1249- 52. https://doi.org/10.1016/j.ajem.2018.03.060

16. Kennedy M, Enander RA, Tadiri SP, Wolfe RE, Shapiro NI, Marcantonio ER. Delirium risk prediction, healthcare use and mortality of elderly adults in the emergency department. J Am Geriatr Soc. 2014;62(3):462-9. https://doi.org/10.1111/jgs.12692 
17. Serpytis P, Navickas P, Navickas A, Serpytis R, Navickas G, Glaveckaite S. Age- and gender-related peculiarities of patients with delirium in the cardiac intensive care unit. Kardiol Pol. 2017;75(10):1041-50. https://doi.org/10.5603/KP.a2017.0122

18. Pereira FB, Lopes MA. Delirium in elderly inpatients admitted to clinical wards Prevalence and investigation of clinical conditions in a Brazilian sample. Dement Neuropsychol. 2018;12(2):152-6. https://doi.org/10.1590/1980-57642018dn12-020007

19. Kotfis K, Szylińska A, Listewnik M. Early delirium after cardiac surgery: an analysis of incidence and risk factors in elderly ( $\geq 65$ years) and very elderly ( $\geq 80$ years) patients. Clin Interv Aging. 2018;13:1061-70. https://doi.org/10.2147/CIA.S166909

20. Oliveira CP, Santos IMG, Rocca AR, Dobri GB, Nascimento GD. Epidemiological profile of elderly patients treated in the emergency room of a university hospital in Brazil. Rev Med. 2018;97(1):44-50. https://doi.org/10.11606/issn.1679-9836.v97i1 p44-50

21. Sri-on J, Tirrell GP, Vanichkulbodee A, Niruntarai S, Liu SW. The prevalence, risk factors and short-term outcomes of delirium in Thai elderly emergency department patients. Emerg Med J. 2016;33(1):17-22. https://doi.org/10.1136/emermed-2014-204379

22. Dani M, Owen LH, Jackson TA, Rockwood K, Sampson EL, Davis D. Delirium, Frailty, and Mortality: Interactions in a Prospective Study of Hospitalized Older People. J Gerontol A Biol Sci Med Sci. 2018;73(3):415-8. https://doi.org/10.1093/gerona/glx214

23. Bastos AS, Beccaria LM, Silva DC, Barbosa TP. Identification of delirium and subsyndromal delirium in intensive care patients. Rev Bras Enferm. 2019;72(2):463-7. https://doi.org/10.1590/0034-7167-2017-0240

24. Oliveira DS, Fernandes FM, Silveira MG, Ventura MM. Factors related to delirium and mortality in older adults with femur fracture on an orthopedic unit. Geriatr Gerontol Aging. 2019;13(2):75-9. https://doi.org/10.5327/Z2447-211520191900020

25. Collins N, Blanchard MR, Tookman A, Sampson EL. Detection of delirium in the acute hospital. Age Ageing. 2010;39:131-135. https://doi. org/10.1093/ageing/afp201

26. Shinozaki G, Bormann NL, Chan AC. Identification of Patients With High Mortality Risk and Prediction of Outcomes in Delirium by Bispectral EEG. J Clin Psychiatry. 2019;80(5):19m12749. https://doi.org/10.4088/JCP.19m12749

27. Ma IC, Chen KC, Chen WT. Increased Readmission Risk and Healthcare Cost for Delirium Patients without Immediate Hospitalization in the Emergency Department. Clin Psychopharmacol Neurosci. 2018;16(4):398-406. https://doi.org/10.9758/cpn.2018.16.4.398

28. Stelmokas J, Gabel N, Flaherty JM. Delirium Detection and Impact of Comorbid Health Conditions in a Post-Acute Rehabilitation Hospital Setting. PLoS One. 2016;11(11):e0166754. https://doi.org/10.1371/journal.pone.0166754

29. Émond M, Boucher V, Carmichael PH. Incidence of delirium in the Canadian emergency department and its consequences on hospital length of stay: a prospective observational multicentre cohort study. BMJ Open. 2018;8(3):e018190. https://doi.org/10.1136/ bmjopen-2017-018190

30. Parrish E. Delirium Superimposed on Dementia: Challenges and Opportunities. Nurs Clin North Am. 2019;54(4):541-550 https://doi. org/10.1016/j.cnur.2019.07.004

31. Morley C, Unwin M, Peterson GM, Stankovich J, Kinsman L. Emergency department crowding: a systematic review of causes, consequences and solutions. PLoS One. 2018;13(8) 13(8):e0203316. https://doi.org/10.1371/journal.pone.0203316

32. Castilho DEC, Silva AEBC, Gimenes FRE, Nunes RLS, Pires ACAC, Bernardes CA. Factors related to the patient safety climate in an emergency hospital. Rev Latino-Am Enfermagem. 2020;28:e3273. https://doi.org/10.1590/1518-8345.3353.3273

33. Rothman K, Greenland S, Lash T. Epidemiologia Moderna. Porto Alegre: Artmed; 2011. 184 p. 